\title{
Mix design process of polyester polymer mortars modified with recycled GFRP waste materials
}

\author{
M.C.S. Ribeiro, A. Fiúza, A.C.M. Castro, F.G. Silva, M.L. Dinis, J.P. Meixedo, M.R. Alvim
}

\begin{abstract}
A B S T R A C T
In this study, the effect of incorporation of recycled glass fibre reinforced plastics (GFRP) waste materials, obtained by means of shredding and milling processes, on mechanical behaviour of polyester polymer mortars (PM) was assessed. For this purpose, different contents of GFRP recyclates, between $4 \%$ up to $12 \%$ in weight, were incorporated into polyester PM materials as sand aggregates and filler replacements. The effect of the addition of a silane coupling agent to resin binder was also evaluated. Applied waste material was proceeding from the shredding of the leftovers resultant from the cutting and assembly processes of GFRP pultrusion profiles. Currently, these leftovers as well as non-conform products and scrap resulting from pultrusion manufacturing process are landfilled, with additional costs to producers and suppliers. Hence, besides the evident environmental benefits, a viable and feasible solution for these wastes would also conduct to significant economic advantages.

Design of experiments and data treatment were accomplish by means of full factorial design approach and analysis of variance ANOVA. Experimental results were promising toward the recyclability of GFRP waste materials as partial replacement of aggregates and reinforcement for PM materials, with significant improvements on mechanical properties of resultant mortars with regards to waste-free formulations.
\end{abstract}

Keywords:

Glass fibre reinforced polymers

Wastes

Recycling

Concrete-polymer composite materials

Mix design

\section{Introduction}

Worldwide volume production and consumption of fibre reinforced polymers (FRP) have increased in the last decades in several fields, mostly in the construction, automobile and aeronautic sectors [1-3]. The high strength to weight ratio, ease of installation, low maintenance and corrosion resistance, make FRP based materials a competitive alternative to steel, metals and other similar materials. Other important drivers of the grow of these composite materials have been the reduced weight and parts consolidation that the materials offers, as well as its inherent anisotropy that allows design flexibility and tailor made characteristics [4].

Despite all the advantages associated to FRP based products, the increasing production and use also generates an increasing amount of FRP waste. Thus, recyclability of both the production waste and end-of-life products became an important and concerning issue. Whereas thermoplastic FRPs can be easily recycled by remelting and remoulding, recyclability of thermosetting FRPs is a more difficult task due to the 3-dimentional crosslink nature of resin matrix $[5,6]$. Presently, most of the thermoset based FRP waste is still being incinerated or landfilled, leading to negative environmental impacts and additional costs to FRP producers and suppliers. However, it is expected that impending waste management legislation will put more stress on the industry to address the options available for FRP waste management. Such waste legislation focuses on dealing with waste through waste hierarchy and will therefore put more pressure on solving FRP waste management through recycling and reuse. In the near future, due to these more restrictive waste management legislations, FRP suppliers might lose their market share to metals and other industries if they cannot ensure that their FRP components can be reused or recycled at the end of their life [7]. Thus, at the present time, the perceived lack of recyclability of thermoset FRP composite materials is increasingly important and seen as a key barrier to the development or even continued use of these materials in some markets [8].

Under this framework, the increased awareness of environmental matters and the search for further sustainable materials have promoted the proposal and analysis of several recycling techniques, mainly for GFRP and CFRP waste materials. A complete review of current recycling technologies for thermoset composites can be found in Pickering [6]. Thermal and/or chemical recycling methods with partial fibre and energy recovering have been proposed mostly for CFRP due to the inherent economic value of carbon fibre reinforcement; whereas for GFRP based products, mechanical recycling by shredding and milling processes with 
reduction to fibrous and/or powdered products has been considered as a more economically viable recycling method. This last process presents important advantages over the former ones as follows: (a) there is no atmospheric pollution by gas emission; (b) much simpler equipment is required when compared with the ovens necessary for thermal recycling processes; and (c) does not require the use of chemical solvents with subsequent environmental impacts. As drawbacks, both the low economic value of the recyclates obtained by this process (a mix of powdered and fibrous material, which must compete with virgin reinforcing fibres and filler materials) and safety issues (e.g., risk of ignition during gridding process due to the presence of initiator plus promoter not consumed during polymerization reaction) can be argued. Nevertheless, ensuring that economically viable end-use applications for the recyclates exist, mechanical recycling is so far considered the most suitable recovery technique at least for relatively low cost and promoter-free FRP materials $[6,9,10]$.

Although considered green and friendly materials, mechanically recycled GFRP wastes remain however, mired by the scarceness of cost-effective end-use applications and clearly developed recycling routes (logistics, infrastructures and recycling facilities) between both type of industries: waste producers and potential consumers for the recyclates. Over the last 20 years, several attempts have been made in order to solve this issue by putting considerable effort in the investigation of promising end-use applications for ground GFRP wastes. Filler material for artificial wood [11], high density polyethylene (HDPE) plastic lumber [12], rubber pavement blocks [13], dense bitumen macadam [14] and for bulk/sheet (BMC/SMC) moulding compounds [6,10]; reinforcement for wood particleboard [15]; and core material for textile sandwich structures [16], were some of the foreseen potential recycling applications. Most of them have not succeeded for one or both of the following reasons: (a) tendency of the recyclate addition to negatively affect the mechanical properties of final composite; and (b) negative cost balance, where mechanical recycling and sorting operational costs outweighed the market value of the virgin product (chopped glass fibres and calcium carbonate) [6,10,17].

Although there are many potential applications among composite materials, the most extensive research work has been carried out on Portland cement concrete in which mechanically recycled GFRP waste, and more rarely CFRP waste, have been incorporated either as reinforcement, aggregate or filler replacement [18-24]. In addition to environmental benefits, as function of specific mix design formulation, reported added values include slight to strong decreases of permeability with subsequent improved durability $[19,20,22]$, less drying shrinkage [19-21], and a global cost reduction of raw materials. In some particular cases, for lower sand replacement ratios, slender increases on compressive, splitting tensile and/or flexural strengths were observed [19,24]. However, most of the times some undesirable features were also noticed such as significant losses in the mechanical properties (mainly due to high water-cement ratio required to achieve the desirable workability) [18,20-22], higher wear loss [22] and weak adhesion at recyclate-binder interface [24]. In addition, depending upon glass fibre nature, some incompatibility problems derived from alkalis silica-reaction may even occur [20].

These limitations, by and large resultant from the use of a cementious binder as matrix, could be avoided using a cementless concrete as host material like polymer based concrete (PC) materials.

PC materials have gained an increasing research interest due to their wide range of possible applications in civil construction [2527]. In this class of materials, a thermoset resin is used as binder of natural or artificial aggregates, replacing the paste of Portland cement/water of conventional hydraulic concretes [28]. The initial applications of PC during the late 1950s, were the production of building cladding and cultured marble products. However, the excellent properties exhibited by these materials rapidly promoted the spread of its end-use applications. Its rapid curing, excellent bond to concrete and steel reinforcement, high strength and durability made it a very attractive repair material. As a mortar, it can be placed with thickness less than $10 \mathrm{~mm}$. Overlays in PC for bridge surfaces and floors have also become widely used because of their ability to use thin layers, fast curing time, very low permeability, and high resistance to chemical and frost attack. Precast components are another excellent use of the material: the high strength to weight ratio, good damping properties, moldability and ability to form complex shapes make PC and PMs particularly suitable for these applications [25-32]. Though, currently, the main asset of PC materials over conventional concretes is their great ability for incorporating recycled waste products, mainly owned to hermetic nature of resin matrix [33]. Recycling and waste encapsulation constitute nowadays an emerging branch market for PCs. Most of the successful applications reported involved either industrial by-products or recyclates derived from end-of-life products. Industrial wastes, such as fly ash, slag, wood shaves, cork powder and cork granulates, tire rubber, contaminated foundry sands, plastic chips from used polyethylene and polyvinyl chloride films, as well as plastic granulates proceeding from milled waste electrical cables, have been successfully used for replacing or partially replacing the filler and mineral aggregate components in PC materials [33-38].

\subsection{Research significance}

Despite the relative large amount of research work undertaken on recycled wastes in polymer based concretes, until now, no studies have focused on the incorporation of FRP recyclates into PCs. Seeking to fill this gap, the aim of the present work is to explore a potential waste management solution for GFRP waste (scrap, by-products and end-life products) as reinforcement, aggregate or filler replacement for polymer based mortars (PM).

Compared to related end-use applications in cementicious based concrete materials, which have been investigated in several research studies as previously reported [18-23], the proposed solution is expected to overcome some of the problems found (already mentioned above in this paper). Added value of recycling solution was assessed by means of flexural and compressive loading capacity of GFRP admixed mortars with regard to unmodified PMs.

Applied GFRP waste material was supplied by a local pultrusion manufacturing company (ALTO - Perfis Pultrudidos Lda.). It was proceeding from the leftovers (edges and small pieces) that resulted from the cutting and assembly processes of pultrusion profiles during building sites (Fig. 1). Currently these leftovers, as well as non-conform products and scrap resulting from pultrusion manufacturing process (around 7\% of total annual production of 40 ton) are landfilled, with an annual cost estimated to be $4000 €$ per year. Thus, besides the evident environmental benefits, a viable and feasible solution for these wastes would also conduct to some economic advantages.

One of the main common problems in the design process of composite materials modified with recycled wastes, depending upon waste nature, arises from lack of bond between resin matrix and recyclates $[10,39,40]$. In this study, in order to prevent this undesirable feature also detected in the previous experiments carried out by the present team [41], the effect of the incorporation of an adhesion promoter was also investigated and considered as a material factor. The Design of Experiments (DoE) methodology, which has been applied in recent years with success to design and as an optimization process of composite materials [42-45], was also applied in this study. Planning of experiments and data treatment was accomplished by means of mix-level full factorial 

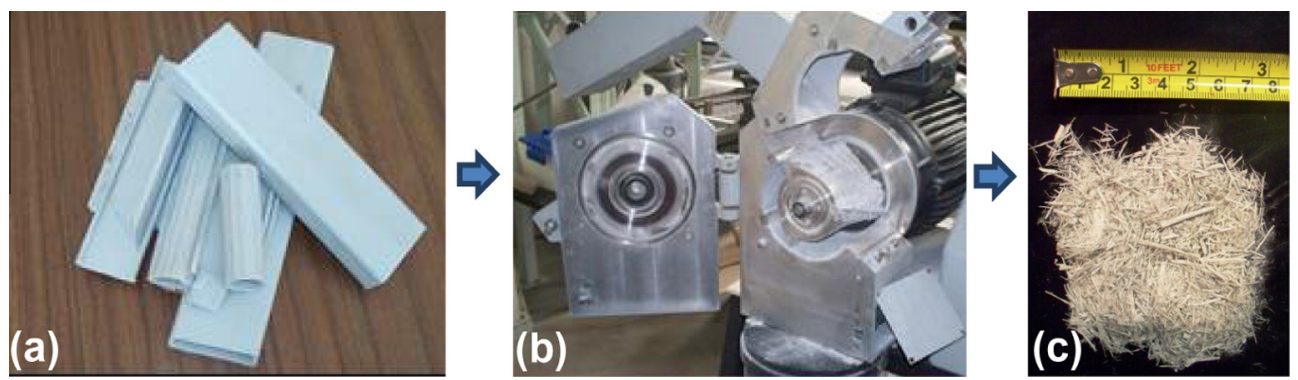

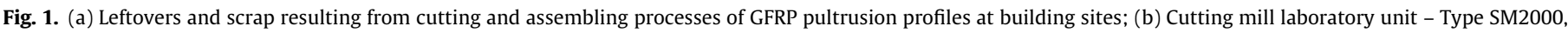
Retsch, and (c) Milled GFRP waste.

design and analysis of variance ANOVA. The use of factorial experiment design, instead of the one-factor-at-a-time method, is efficient at allowing the assessment of the effects and possible interactions of the different material factors involved.

\section{Experimental program}

Polymer mortar specimens were prepared by mixing an unsaturated polyester resin $(20 \% \mathrm{w} / \mathrm{w})$ with different sand aggregates/ GFRP waste ratios. Processed GFRP wastes were used as partial substitute for sand aggregates at the proportion of $4 \%, 8 \%$ and $12 \%$ in weight of total mass. The limits of range variation of this parameter were established taking into account the main goal of this work: the development of a cost-effective end-use application for GFRP recyclates. Hence, a compromise between as high as possible recycled material content and reasonable mechanical properties must be obtained. Since the resin binder is the most expensive component on PC materials, and as such, it is intended to keep its content as low as possible $(20 \% \mathrm{w} / \mathrm{w})$, the use of higher sand replacement ratios in weight would lead to excessively 'dry' mixtures with lack of cohesiveness, and consequently, with poorer mechanical properties. It is important to bear in mind that the progressive increases of sand replacement by GFRP recyclates in weight also leads to progressive decreases of binder content by total volume, once the specific weight of GFRP recyclates is significant lower than that of sand aggregates.

Plain mortar specimens were also casted and tested in order to compare mechanical and functional properties over those of GFRP waste admixed mortars. The composition of plain formulation was designed in previous work on statistical significance of synergetic effects between material components [46], in which a polyester resin with similar viscosity, physical and mechanical properties was applied. In order to investigate the effect of the adhesion promoter between organic matrix and inorganic aggregates (sand plus recyclates), a second series of experiments was carried out in which $1 \%$ of active silane coupling agent by weight of resin matrix was added to all formulations in analysis. It is expected that the incorporation of the silane chemical agent will also have an important role on the workability and homogeneity of the final mixtures since it tends to reduce the viscosity of the mixture, promotes a better dispersion of filler fraction and improves wet-out of overall aggregates in the resin binder as reported by Chmielewska et al. [47].

\subsection{Raw materials}

Commercially available unsaturated polyester resin (Aropol ${ }^{\circledR}$ FS3992, Ashland ${ }^{\circledR}$ ) with a styrene content of $42 \%$ was applied as polymer binder. This high reactivity resin system is the same applied as matrix in the manufacturing process of GFRP pultrusion profiles produced by Alto. Its application in this study as binder matrix was justified in order to prevent possible incompatibilities with the GFRP waste admixtures. The polymerization process was induced by cobalt octoate $(0.5 \mathrm{phr})$ and $50 \%$ methyl ethyl ketone peroxide solution ( $2 \mathrm{phr}$ ). Physical and mechanical properties of resin binder, as supplied by the manufacturer are presented in Table 1.

An organofunctional silane chemical solution (Dow Corning ${ }^{\circledR} \mathrm{Z}$ 6032 ), with $40 \%$ of active silane in methanol, was applied as adhesion promoter of resin binder to inorganic sand aggregates and GFRP recyclates. Z-6032 silane contains a vinylbenzyl and amine organic groups and a trimethoxysilyl inorganic group. As a coupling agent, it can be used either as an additive to a polymer or as pre-treatment on inorganic surfaces. In this study, the Z-6032 silane solution, when applied, was previously mixed with resin system prior to sand and GFRP recyclates addition.

A siliceous foundry sand (silica content $>99.0 \%$ ) that has a rather uniform particle size, an average diameter of $245 \mu \mathrm{m}$ and a fineness modulus of 3.04, was used as fine aggregate. This silica sand is extracted/processed by Sibelco, Lda., and has been commercialized under the trade name of SP55. Particle size distribution of foundry sand is presented ahead in this paper in Fig. 2.

The GFRP waste materials supplied by the local manufacturing company was comprised essentially of an unsaturated polyester resin (Aropol ${ }^{\circledR}$ FS3992) loaded with calcium carbonate and reinforced with E-glass roving (4800 Tex), continuous filament mat (25 Tex) and surfacing veils. Applied GFRP waste was proceeding from the same type of pultrusion profiles $\left(\rho=1.91 \mathrm{~g} \mathrm{~cm}^{-3}\right)$. Shredded GFRP waste was further processed by milling using a Retsch SM2000 cutting mill laboratory unit shown in Fig. 1. Obtained mechanically-recycled products consist of a mix of powdered and fibrous material with different quantities of varying length of glass fibres and bulk particulate material (Fig. 1).

GFRP recyclates were characterized with regard to organic and inorganic fraction contents, and particle size distribution. Burning tests carried out on five random samples revealed an average inorganic content of $71 \%(\mathrm{w} / \mathrm{w})$ corresponding to glass fibre $(55 \% \mathrm{w} / \mathrm{w})$ and calcium carbonate, $(16 \% \mathrm{w} / \mathrm{w})$ and an average resin content of $29 \%(w / w)$. Particle size distribution, obtained by sieving and laser diffraction techniques, revealed a wide range of particle sizes (or fibre diameter) between $1.5 \mu \mathrm{m}$ up to $2500 \mu \mathrm{m}$, with an average diameter of $950 \mu \mathrm{m}$ and a fineness modulus of 2.69 (Figs. 2 and

Table 1

Physical and mechanical properties of cured resin (Aropol FS3992).

\begin{tabular}{lll}
\hline Resin properties & Method & Value \\
\hline Heat defl. temp. $\left({ }^{\circ} \mathrm{C}\right)$ & ASTM D-648 & 95 \\
Barkoll hardness & ASTM D-638 & 45 \\
Tensile strength $(\mathrm{MPa})$ & ASTM D-790 & 60 \\
Flexural strength (MPa) & ASTM D-2583 & 110 \\
Elongation at break $(\%)$ & ASTM D-638 & 3.2 \\
\hline
\end{tabular}




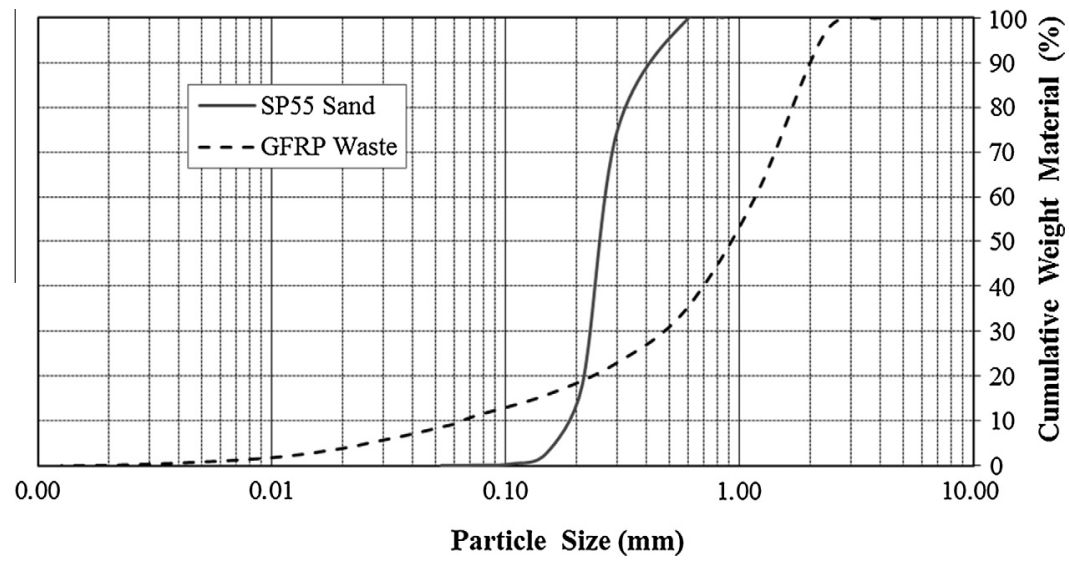

Fig. 2. Particle size distributions of sand aggregates and GFRP recyclates.

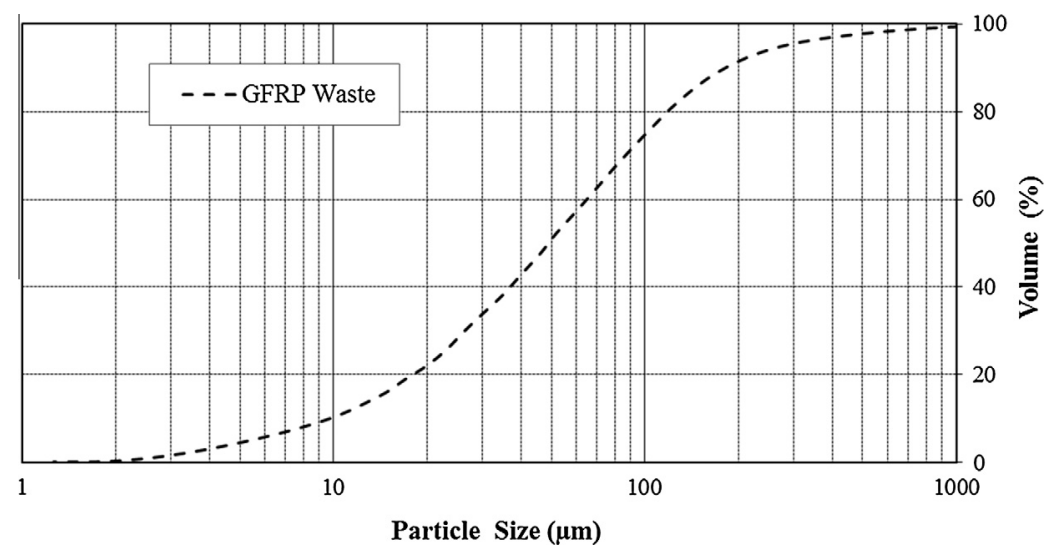

Fig. 3. Volumetric particle size distribution of filler fraction of GFRP recyclates obtained by laser diffraction technique.

3). Previous research work carried out by the present research team focused on the effect of two different size grades of FRP waste recyclates on the mechanical properties of polyester PMs showed that this particle size distribution leads to improved global results of resultant modified mortars [41].

\subsection{Trial program and testing}

Eight different PM formulations were investigated varying the content of both the silane coupling agent ( $0 \%$ and $1 \%$ by weight of resin content) and the GFRP waste admixture (0\%, $4 \%, 8 \%$ and $12 \%$ by weight of total mass), hereinafter designated by material factors ' $S$ ' and ' $W$ ', respectively. Experimental trials are presented in Table 2 and correspond to a two-factor $\left(2^{1} \times 4^{1}\right)$ full factorial design with respectively two and four levels of variation.

PM formulations with the specified mix proportions were casted into standard prismatic moulds $\left(40 \times 40 \times 160 \mathrm{~mm}^{3}\right)$

Table 2

Mix proportions $(\mathrm{w} / \mathrm{w})$ of trial formulations.

\begin{tabular}{lllll}
\hline Experimental trials & Resin $(\%)$ & Sand (\%) & Silane $^{\mathrm{a}}(\%)$ & GFRP $(\%)$ \\
\hline 1. W-0 & 20 & 80 & 0 & 0 \\
2. W-4 & 20 & 76 & 0 & 4 \\
3. W-8 & 20 & 72 & 0 & 8 \\
4. W-12 & 20 & 68 & 0 & 12 \\
5. WS-0 & 20 & 80 & 1 & 0 \\
6. WS-4 & 20 & 76 & 1 & 4 \\
7. WS-8 & 20 & 72 & 1 & 8 \\
8. WS-12 & 20 & 68 & 1 & 12
\end{tabular}

${ }^{a}$ By weight of resin content. according to RILEM recommendation CPT PC-2:1995 [48]. Four prismatic specimens were cast for each formulation. All test specimens were allowed to cure for $24 \mathrm{~h}$ at $30^{\circ} \mathrm{C} / 50 \% \mathrm{RH}$, and then post-cured at $80^{\circ} \mathrm{C}$ for $3 \mathrm{~h}$, before being tested in bending and compression at the same age after a minimum conditioning period of $24 \mathrm{~h}$ at $23^{\circ} \mathrm{C} / 50 \% \mathrm{RH}$.

PM specimens were tested in three-point bending up to failure at the loading rate of $1 \mathrm{~mm} \mathrm{~min}{ }^{-1}$, over a span length of $100 \mathrm{~mm}$, according to RILEM CPT PCM-8:1995 standard test method [49]. One of the two leftover parts of each broken specimen in bending were tested afterwards in compression at the loading rate of $1.25 \mathrm{~mm} \mathrm{~min}^{-1}$, following the procedure described in UNE 83821:1992 standard [50]. Applied test operating methods in flexure and compression were similar to those specified in EN 196$1: 2005$ [51], which is the test standard commonly used for the determination of strength of cement mortars. Samples of broken specimens after being tested in bending are shown in Fig. 4 and both flexural and compressive testing set-ups are presented in Fig. 5.

\section{Experimental results}

\subsection{Experimental test results}

The mechanical strengths obtained for each trial formulation are detailed in Table 3. Presented values represent the average flexural and compressive strengths obtained for the four replicates and correspondent standard deviations. The typical load-deflection and load-deformation curves obtained during flexural and compression tests are plotted in graphs of Figs. 6 and 7, respectively. 

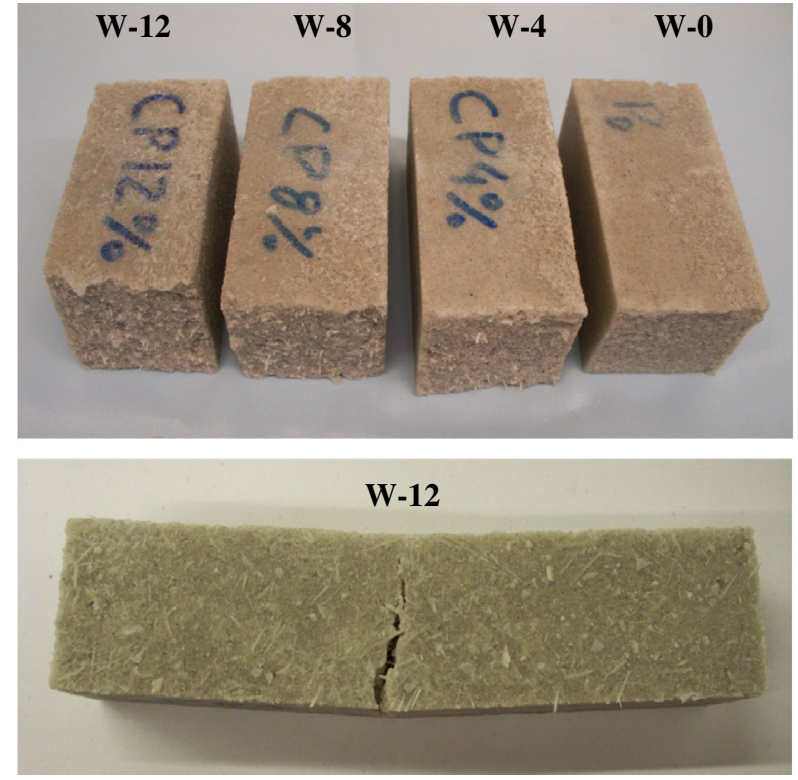

Fig. 4. Samples of broken PM specimens after being tested in bending ( $\mathrm{W}$ test series).

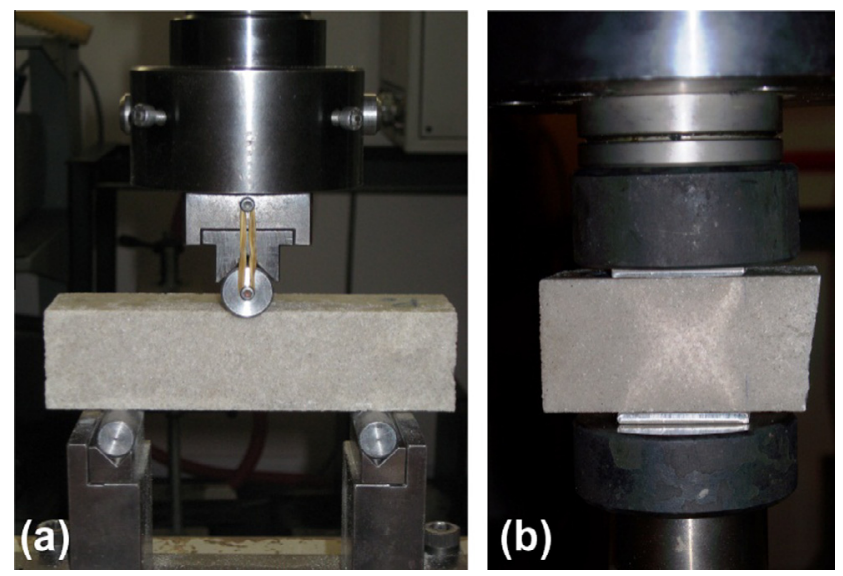

Fig. 5. (a) Three-point bending test set-up (100 mm span length); (b) compressive test set-up (loading plates with $40 \times 40 \mathrm{~mm}^{2}$ surface area).

Table 3

Flexural and compressive test results.

\begin{tabular}{llc}
\hline Experimental trials & Flex. strength $(\mathrm{MPa})$ & Comp. strength $(\mathrm{MPa})$ \\
\hline 1. W-0 & $25.17 \pm 0.74$ & $76.89 \pm 0.89$ \\
2. W-4 & $27.74 \pm 0.31$ & $83.27 \pm 2.02$ \\
3. W-8 & $26.29 \pm 0.99$ & $86.22 \pm 2.12$ \\
4. W-12 & $26.18 \pm 0.51$ & $82.81 \pm 2.91$ \\
5. WS-0 & $36.00 \pm 0.53$ & $81.29 \pm 0.74$ \\
6. WS-4 & $40.35 \pm 0.93$ & $97.52 \pm 1.00$ \\
7. WS-8 & $41.70 \pm 1.81$ & $104.69 \pm 0.66$ \\
8. WS-12 & $39.28 \pm 1.44$ & $82.42 \pm 2.42$ \\
\hline
\end{tabular}

In order to provide a clear comparison basis, for each mechanical test, only one representative curve of each trial formulation is presented. The total sets of curves corresponding to the four replicates tested for each formulation are presented individually in Appendix A (Fig. A1).

The main effects of each factor and their interactions can be studied by the level average response analysis of raw data. The analysis is done by averaging the raw data at each level of each parameter (marginal means) and plotting the value in graphical form (response graphics). The level average responses help in analysing the trend of both the flexural and mechanical performances with respect to the variation of the factor or interaction under study. The main effects of each factor and the interaction effect across the factors are highlighted in response graphics displayed in Figs. 8-10.

Response graphics allow for the evaluation of the relative importance of each factor, or interaction, in a much easier way than the numeric values of the effects. For the main effects, the interpretation of the response graphics is straightforward. Each point in each graphic represents the average response for a certain level of the factor. The numeric value of the effect is the difference between the two points: the higher the difference, the higher the influence of the factor. To analyse the response graphics of interactions effects, the principal effects of the factors involved must be ignored and attention should be focused on their interactions. The interaction is graphically defined by the parallelism between the two lines (or group of lines): the smaller the parallelism, the higher the interaction [52].

\subsection{Analysis of variance - ANOVA}

Analyses of variance for the properties in study are given in Tables 4 and 5 in terms of the sum of squares (SS), degrees of freedom $(\mathrm{dF})$, mean squares values (MS), $F$-test ratio $(F), p$-values and percent contribution $(P)$. The obtained computed values allow for the assessment of the relative significance of each factor and interaction on target responses of the experiment.

The F-test statistic is a measure of variance and allows for the comparison between variances of several groups. For a certain chosen level of significance, the $F$-test allows for the verification of the effects that are significantly different from zero. The $F$-test statistic $\left(F_{0}\right)$ is calculated as the ratio between the mean of squares of the group (factor or interaction) and the mean of squares of the random error [52]. The critical $F$-value $\left(F_{\text {CRIT }}\right)$ can be found on percentage points of $F$-distribution tables as a function of the level of significance $(\alpha)$ and the degrees of freedom of the numerator and denominator. If $F_{0}$ is greater than $F_{\mathrm{CR} I T}$, then the null hypothesis is rejected which indicates that the effect or interaction is significant in statistical terms. If $F_{0}$ is less than $F_{\mathrm{CRIT}}$, then the null hypothesis is accepted, which means that the groups are not significantly different, i.e., the effect or interaction is not significant. $F_{\text {CRIT }}$ was determined for a significance level of $5 \%$. This level of significance is commonly used in practice and it represents the probability of accepting an effect or interaction as significant, when the null hypothesis is falsely rejected (also known as a Type I error) [52].

The percent of contribution, shown in the last columns of Tables 4 and 5, indicates the relative influence of the factor and/or interaction on the global variation observed. It is derived from the expected value of the variance due exclusively to that factor or interaction The respective percent contributions to global variation $(P)$, are computed as the ratio of the pure sum of squares of the factor or interaction to the total sum of squares (pure sum of squares, here understood as the sum of squares minus the degree of freedom times the error variance), as expressed by the following equation:

$P_{X}(\%)=\left[\left(\mathrm{SS}_{X}-\mathrm{MS}_{E} \cdot \mathrm{df}_{X}\right) / \mathrm{SS}_{T}\right] \times 100$

where $\mathrm{SS}_{X}$ and $\mathrm{df}_{X}$ are, respectively, the sum of squares and degrees of freedom of the factor (or interaction); $\mathrm{MS}_{E}$ is the mean sum of squares associated to the error; and $\mathrm{SS}_{T}$ is the total sum of squares.

It is worth to stress that the parametric approach here applied to test the null hypothesis is valid because the assumptions of ANOVA regarding normality and homogeneity of variances of raw data were met, as demonstrated by Shapiro-Wilk's and Levene's tests results presented in Appendix A [53,54] (Table A1). 

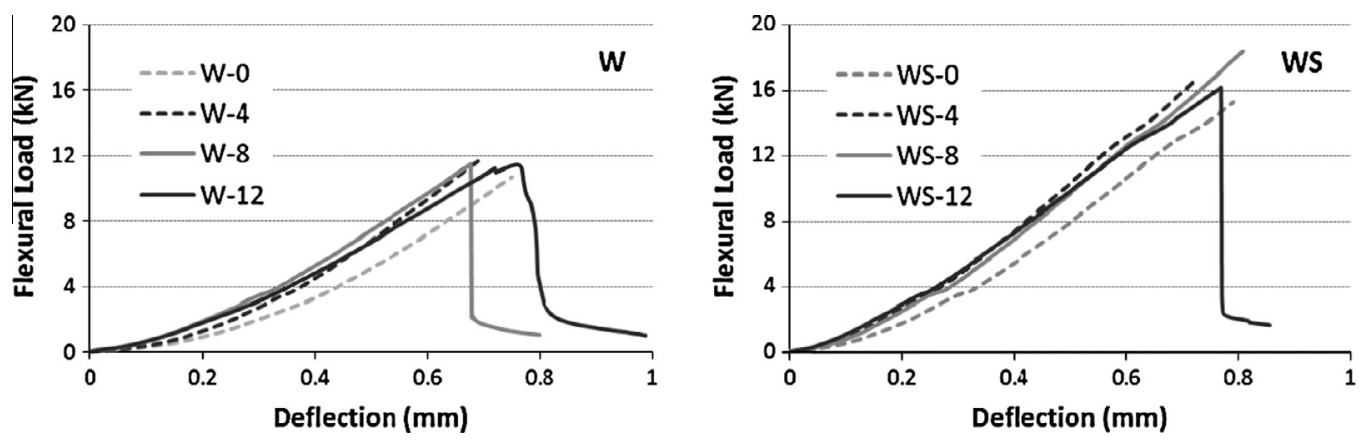

Fig. 6. Representative load-midspan deflection curves obtained during bending tests of W and WS test series formulations.
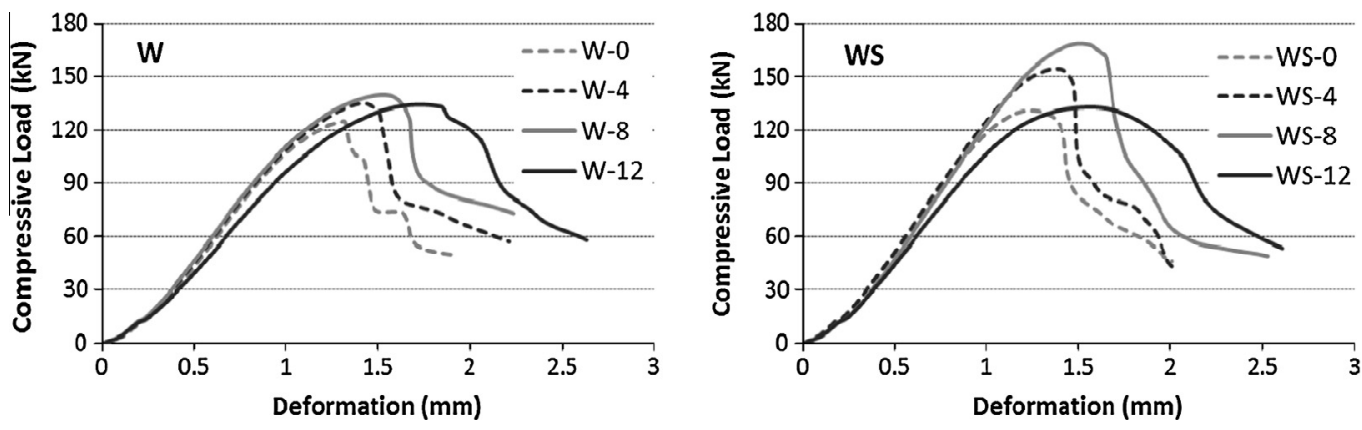

Fig. 7. Representative load-deformation curves obtained during compression tests of W and WS test series formulations.

\section{Discussion}

\subsection{Effect of material factor GFRP waste content ('W')}

The obtained experimental test results, shown in Table 3, indicate that the partial replacement of sand aggregates by milled GFRP waste materials in polyester based mortars has an incremental effect on both the flexural and compressive strengths of modified mortars, regardless of the addition amount of GFRP waste and silane coupling agent. Though, the effect of GFRP waste on mechanical strength is clearly more pronounced regarding compressive behaviour than flexural performance, as displayed in responses graphics of the main effect of this factor (Factor ' $W$ ') and confirmed by the analyses of variance:

- The slops of the lines of compressive strength response graphic are sharper, in opposition with the smooth slopes occurring for flexural strength response (see Fig. 8).

- The contribution of this factor to global variance of compressive strength of PMs is higher than $50 \%$, whereas for flexural strength, the contribution does not reach $4 \%$ (see Tables 4 and $5)$.

Although the global improvement effect of GFRP recyclates incorporation on mechanical strength of resultant modified PMs, two distinct trends were observed for this effect according to both the amount of waste addition (or sand replacement) and the mechanical response itself (in compression or in flexure).

Up to $8 \%$ content in waste addition, in general, loading capacities of polymer mortars increase with increasing addition of GFRP waste. Combining the different evaluation criteria (i.e., compressive strength and flexural strength responses) into a single quantity such as the average variation of relative flexural and compressive strengths, averages increases of $12.6 \%$ and $15.3 \%$ were found for the test series with $4 \%$ and $8 \%$ in weight of GFRP waste content, respectively, with regard to control formulations (W-0/ WS-0). Once again, this feature is more pronounced with regard to compressive than flexural behaviour: average compressive strength increases of $14.1 \%$ and $21.5 \%$ corresponding to trial formulations with $4 \%$ and $8 \%$ waste content were observed with regard to waste-free PMs. The almost linear increase of compressive strength with GFRP waste content may be attributed to a more continuous particle size distribution of the mix sand/waste particles. The contribution of GFRP waste powder to filler fraction of sand aggregates, which leads to an inferior void volume for dry-packed aggregate, has a relevant role in this feature. Generally, aggregates mixtures with the maximum bulk density lead to higher strength materials, due to improved aggregate agglomeration. This trend of linear increase of loading capacity with increasing addition of GFRP waste was not verified with regard to flexural behaviour. Average increases on bending capacity of $11.1 \%$ and $10.1 \%$ were found for $4 \%$ and $8 \%$ in weight of GFRP waste additions, respectively. It was expected that the fibrous fraction of GFRP waste would have a significant reinforcing effect and lead to a bigger improvement in flexural strength. Although this expected flexural improvement did actually occur for the test series modified with silane coupling agent, in which progressive increases of $12.1 \%$ and $15.8 \%$ in bending strength were noticed for respectively WS4 and WS- 8 test formulations, a slight decrease in flexural strength was observed for silane-free test series when GFRP waste content was increased from $4 \%$ to $8 \%$. This tendency was kept for further addition amounts of waste (W-12). As shown in Table 3, average flexural strengths of $\mathrm{W}-4, \mathrm{~W}-8$ and $\mathrm{W}-12$ trial formulations are very similar and the observed decreases are very small; therefore, no clear trend on the behaviour of the material can be inferred. Nevertheless, some possible explanations for the observed decreases on flexural strength might be advanced and summarized in the following. In the mixing and casting process of GFRP modified PM specimens, some tendency for the agglomeration of waste fibres was observed, hindering somehow a perfect homogenization of the mixture. This feature, more pronounced with a 

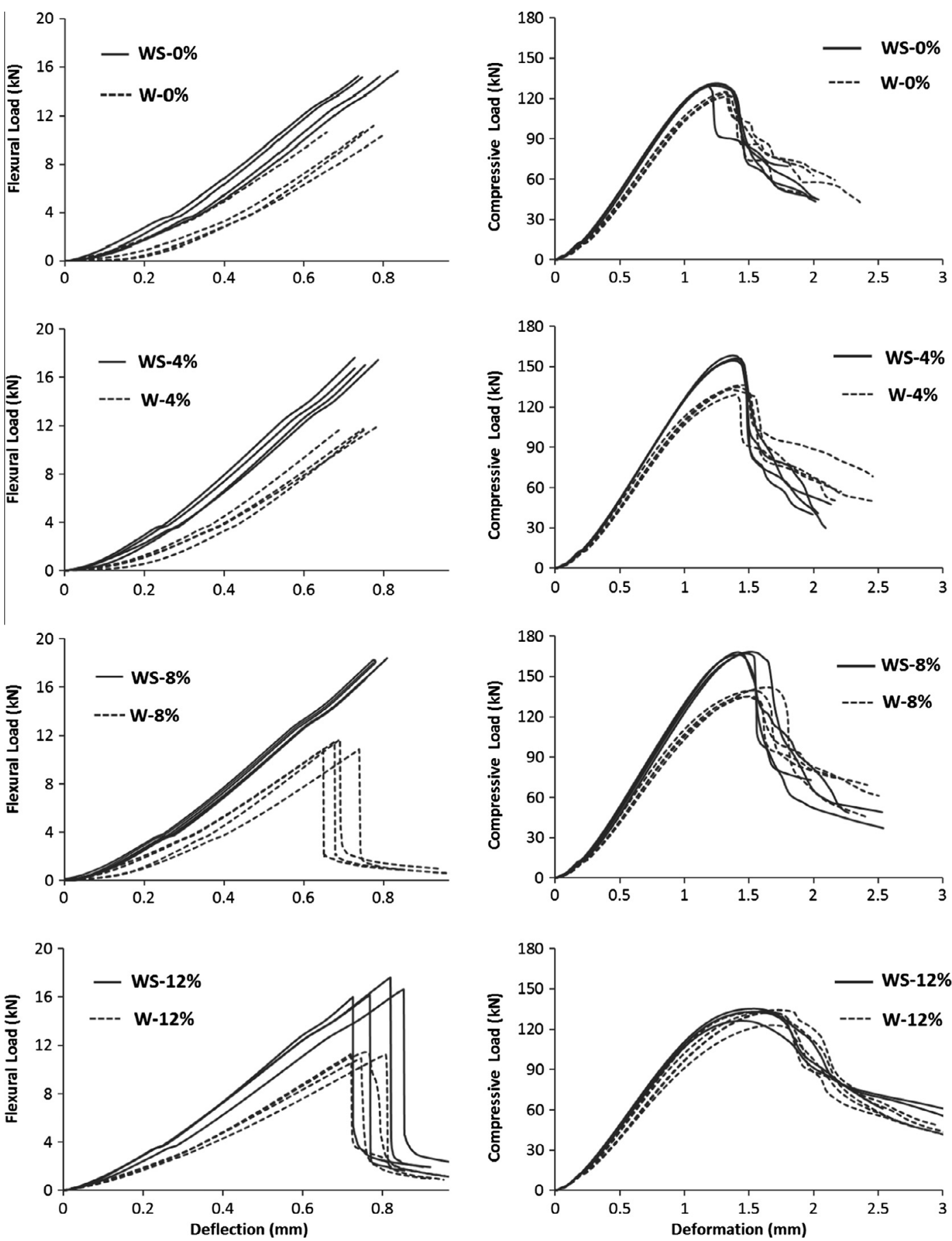

Fig. A1. Load-displacement curves obtained during bending and compression tests (4 replicates for each trial formulation).

higher waste content, led to a non-homogeneous distribution of GFRP waste fibres and might be a possible explanation for obtained results. Another contributing factor might be the presence of larger particles on GFRP recyclates, which tend to be stress raisers, acting as failure initiation sites. Further, considering this assumption is true, this weakness would be more critical under flexural than under compressive stresses. Though, the presence of silane coupling agent might attenuate this feature. This subject should be clarified in a following study that will focus on microstructure analysis of mortar specimens.

Above $8 \%$ content in waste addition, slight to strong decreases occur in both flexural and compressive strengths with regard to PM formulations with lower contents of GFRP waste. However, even so, the mechanical strengths remain higher than those of plain mortars: for $12 \%$ content in waste addition, average increases of $6.4 \%$ and $5.2 \%$ were observed on flexural and compressive strengths of modified mortars, respectively. It must be stressed that the resin content was kept constant at 20\% in weight in all formulations; and, as larger amounts of sand were replaced by GFRP waste throughout the test series (from $0 \%$ to $12 \%$ ), the overall specific surface area of aggregates (sand plus GFRP waste) was progressively increased. Thus, the higher specific surface area of GFRP waste particles with regard to sand particles, which requires higher binder contents for a proper wettability and cohesive bonding, is certainly the main reason for the observed turning point. 

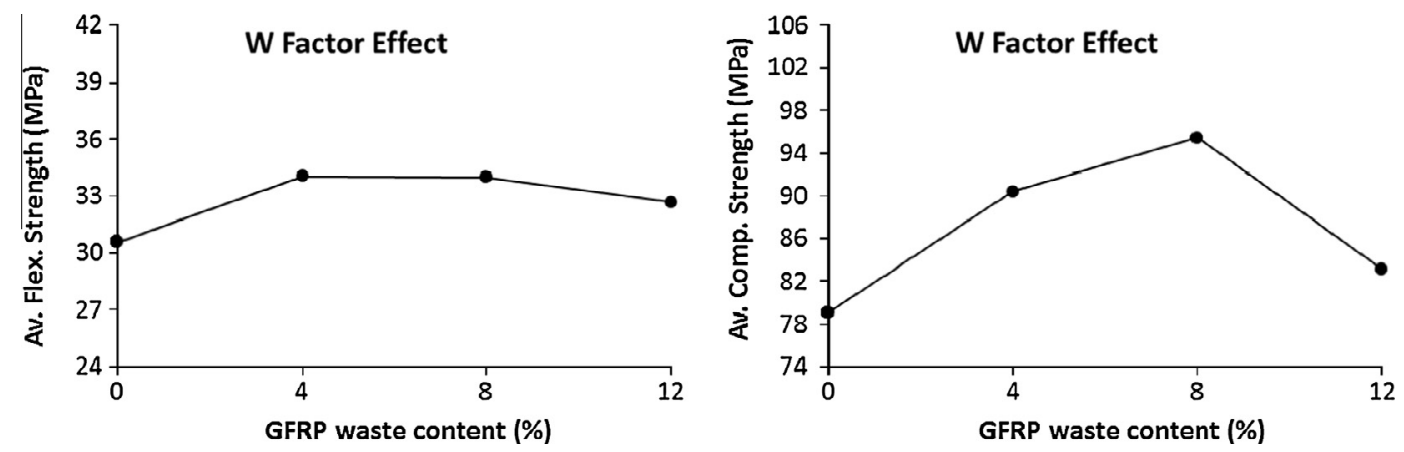

Fig. 8. Main effects of factor 'W' (GFRP waste content) on flexural and compressive strengths of modified PMs.
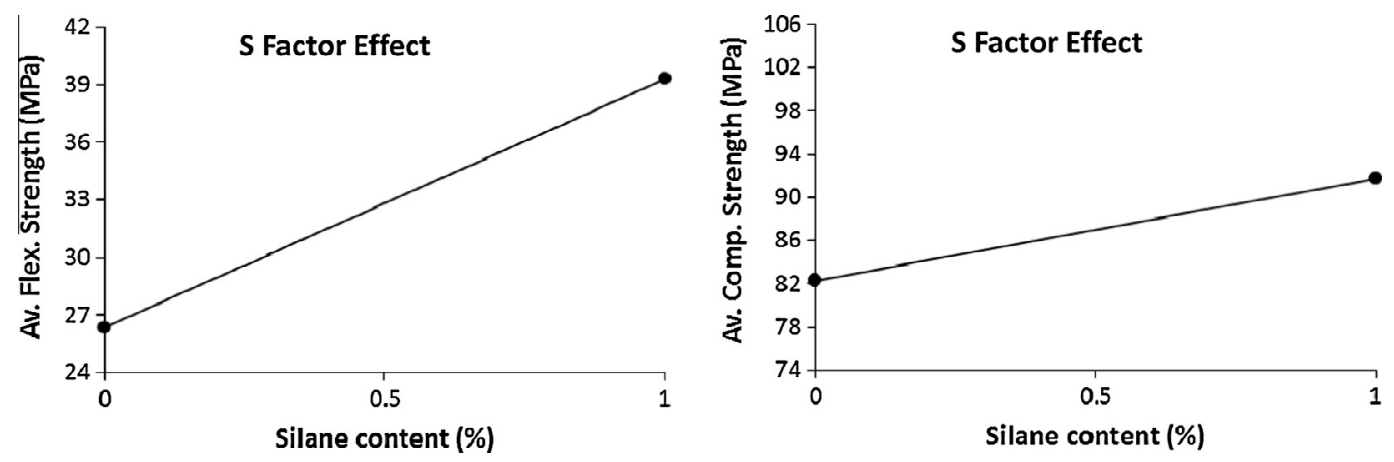

Fig. 9. Main effects of factor 'S' (silane content) on flexural and compressive strengths of modified PMs.
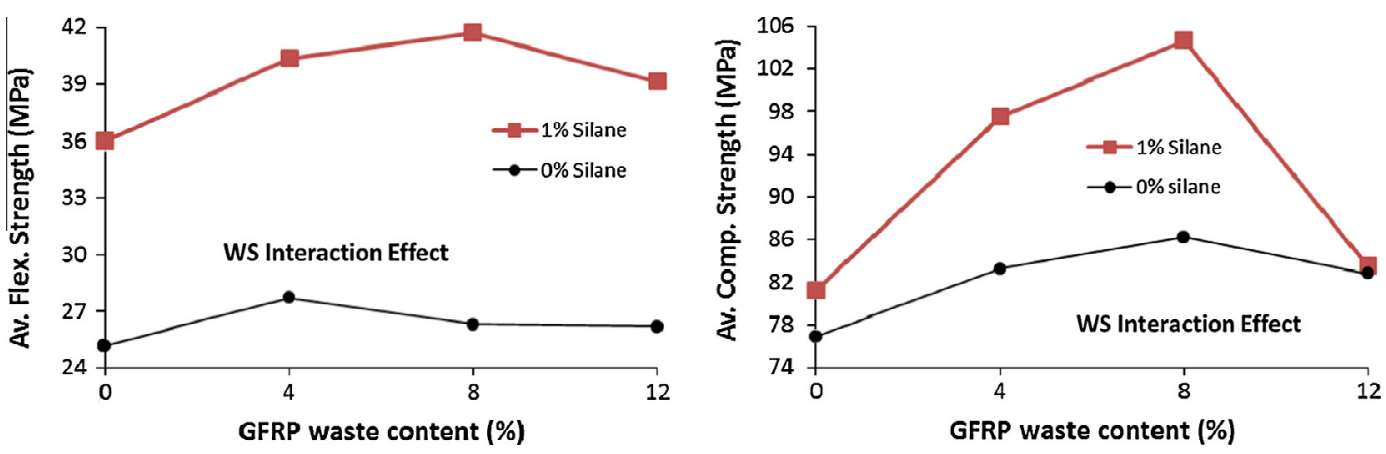

Fig. 10. Interaction effect $\mathrm{W} * \mathrm{~S}$, between silane content and GFRP waste content, on flexural and compressive strengths of modified PMs.

Table 4

Analysis of variance for flexural strength data.

\begin{tabular}{|c|c|c|c|c|c|c|c|}
\hline Source of variation & $\mathrm{SS}\left(\mathrm{MPa}^{2}\right)$ & $\mathrm{dF}$ & $\mathrm{MS}\left(\mathrm{MPa}^{2}\right)$ & $F_{0}$ values & $F_{\text {crit }}$ values & Prob $>F_{0}$ & $P(\%)$ \\
\hline Factor W - waste content & 62.99 & 3 & 21.00 & 19.71 & 3.49 & $\leqslant 0.00005$ & 3.90 \\
\hline Factor S - silane content & 1342.07 & 1 & 1342.07 & 1259.47 & 4.75 & $\leqslant 0.00005$ & 92.29 \\
\hline Interaction $\mathrm{W} * \mathrm{~S}$ & 21.28 & 3 & 7.09 & 6.66 & 3.49 & 0.002 & 1.02 \\
\hline Error & 25.57 & 24 & 1.07 & - & - & & - \\
\hline Total & 1451.92 & 31 & - & - & - & & - \\
\hline
\end{tabular}

Table 5

Analysis of variance for compressive strength data.

\begin{tabular}{|c|c|c|c|c|c|c|c|}
\hline Source of variation & $\mathrm{SS}\left(\mathrm{MPa}^{2}\right)$ & $\mathrm{dF}$ & $\mathrm{MS}\left(\mathrm{MPa}^{2}\right)$ & $F_{0}$ values & $F_{\text {crit }}$ values & Prob $>F_{0}$ & $P(\%)$ \\
\hline Factor W - waste content & 1283.13 & 3 & 427.71 & 167.38 & 3.49 & $\leqslant 0.00005$ & 51.28 \\
\hline Factor S - silane content & 714.23 & 1 & 714.23 & 279.50 & 4.75 & $\leqslant 0.00005$ & 26.68 \\
\hline Interaction $\mathrm{W} * \mathrm{~S}$ & 413.57 & 3 & 137.86 & 53.95 & 3.49 & $\leqslant 0.00005$ & 16.11 \\
\hline Error & 61.33 & 24 & 5.11 & - & - & - & - \\
\hline Total & 2471.26 & 31 & - & - & - & - & - \\
\hline
\end{tabular}


It is likely that larger amounts of GFRP wastes can be incorporated into polyester PMs without significant loss in mechanical properties, ensuring that a proper wetting of the mix sand/recyclates is provided. Though, this would require a higher content of resin binder and, hence, would lead to a less cost-effective recycling solution.

Regarding the effect of GFRP waste content on stiffness of resultant PMs, as inferred by load-deflection curves presented in Fig. 6 , GFRP waste admixed mortars present higher flexural elasticity modulus than unmodified mortars; though, no significant increases on stiffness were found for increasing amounts of GFRP waste content (the slopes of load-deflection curves of W-4, W-8 and $\mathrm{W}-12$, or WS-4, WS-8 and WS-12, are very similar). As shown in Fig. 7, a different trend was found for the effect of GFRP waste content on compressive elasticity modulus. Whereas GFRP waste admixed mortars with waste content up to $8 \%$ present similar stiffness to those of unmodified mortars (although with gain in strain to failure), W-12 and WS-12 trial formulations are less stiff and show an increased ductility.

A less brittle failure of GFRP admixed mortars was also observed, either in bending or in compression. Improved toughness and ductility with GFRP waste content was more pronounced in compression than in flexural, with higher retention of load capacity after peak load.

\subsection{Effect of material factor silane coupling agent ('S')}

As already expected, the incorporation of silane coupling agent had a significant improvement effect on the mechanical strength of PM formulations. The factor's effect is especially remarkable concerning flexural strength response, contributing with more than $92 \%$ for the global variance, as highlighted in response graphic of Fig. 9. The numerical value of the ' $\mathrm{S}$-factor's effect on flexural strength is $12.9 \mathrm{MPa}$, which means that, on average, PMs with an incorporation of $1 \%$ silane, regardless of GFRP waste content, present a flexural strength higher in 12.9 MPa over silane-free PMs. Further, as shown in Fig. A1 in Appendix A. PMs modified with silane coupling agent are also clearly stiffer with respect to bending forces than unmodified mortars. The inherent contribution of the silane coupling agent as an adhesion promoter at interface, between resin matrix and both sand aggregates and glass fibres waste, improved the organic-inorganic phase bridge. This feature, as well as improved wetting of overall aggregates by silane modified resin binder, is for certain the main reason for the observed strong effect of this factor on flexural response of PMs.

With regard to compressive strength response, a minor contribution for global variance was observed (29\%), remaining the GFRP waste content as the most influencing and significant factor. The increase on stiffness due to silane coupling agent addition is also slightly less pronounced in compression than in bending, as inferred by comparison of graphs of Fig. A1.

In general, it can be stated that trial formulations modified with silane are stiffer but with no significant gain in strain to failure.

As only two levels of variation were considered for this factor ( $0 \%$ and $1 \%$ ) no considerations could be done regarding the linear or quadratic effect of the silane content addition on mechanical properties of PMs.

\subsection{Effect of the interaction between factors (' $W * S$ ')}

According to $F$-test results of analyses of variance, and for a significance level of 5\%, the interaction effect between GFRP waste content and adhesion promoter cannot be disregarded either in flexural or in compressive strength responses. Though, the interaction effect is more significant regarding compression than flexural behaviour as stressed by response graphs in Fig. 10 and confirmed by respective contributions to global variation of target responses (the percent contribution to global variation is 4 times higher as regards to compressive strength than that observed with respect to flexural strength).

The significant effect of this interaction is mainly due to dissimilar behaviours of ' $W$ ' and 'WS' test series when GFRP waste content is increased from $8 \%$ to $12 \%$. The drop in compressive strength is very pronounced for PMs modified with silane agent and rather smooth for those without the adhesion promoter. It seems that the enhancement effect of silane coupling agent is somehow weakened for high contents of GFRP waste. The lack of binder required to achieve a proper wetting of the mix sand/recyclates and, hence, to promote an effective bond between the different components, seems to be the main reason for observed decay on compressive strength.

\section{Conclusions}

Experiments were performed in order to determine the effect of both recycled GFRP pultrusion waste admixtures and a silane coupling agent addition on mechanical behaviour of polyester based mortars. Four different levels of GFRP waste content and two different levels of silane coupling agent were investigated, and their influences on target responses (flexural and compressive strengths of modified PMs) were assessed. Based on the obtained results, the following conclusions may be drawn:

- For the trial formulations analysed in this study, the partial replacement of sand aggregates by GFRP waste materials has an incremental effect on both the flexural and compressive strengths of resultant PMs, regardless of the GFRP waste content and silane coupling agent addition.

- Both material factors have a significantly positive effect on the mechanical behaviour of the modified PMs; though, whereas GFRP waste content is the more influencing factor on compressive strength response, contributing with $51 \%$ to global variance of this property; $92 \%$ of the global variance of flexural strength response is due to the addition of the silane coupling agent. Whereas powder fraction of GFRP recyclates has an important role on compressive strength enhancement, by providing an inferior void volume for dry-packed aggregate; the fibrous fraction of GFRP acts mainly as an effective reinforcing material, promoting improved flexural strength as long as a good adhesion at fibre/resin interface is provided.

- Silane coupling agent addition also has a significant improvement effect on stiffness of resultant PMs, either in flexural or in compression.

- The interaction effect between the two factors on mechanical strength of PM formulations cannot be disregarded, especially with respect to compressive strength response for GFRP waste contents above $8 \%(\mathrm{w} / \mathrm{w})$.

- Combining the different evaluation criteria, flexural and compressive strength responses, $8 \%$ in weight of GFRP waste content constitutes the turning point value on the trend of the mechanical behaviour of the modified PM materials. The best compromise combination of factors' levels that maximize both flexural and compressive strengths of modified PMs is achieved for $8 \%(w / w)$ of sand replacement by GFRP waste recyclates, and incorporation of $1 \%$ of active silane to resin binder.

The findings of this study showed a viable technological option for improving the quality of GFRP filled polymer mortars, thus opening a door to selective recycling of GFRP waste and its use in the production of concrete-polymer based products. However, further studies will be necessary and are foreseen in order to define efficient methods to prevent fibres agglomeration during mixing 
Table A1

Shapiro-Wilk's and Levene's test results.

\begin{tabular}{|c|c|c|c|c|c|}
\hline & Test & Statistic & df1 & $\mathrm{df} 2$ & $p$-Value \\
\hline \multirow[t]{2}{*}{ Compression response } & Shapiro-Wilk normality test & 0.9577 & - & - & 0.2054 \\
\hline & Levene's test for equality of variances & 2.0990 & 7 & 24 & 0.0832 \\
\hline \multirow[t]{2}{*}{ Flexural response } & Shapiro-Wilk normality test & 0.9542 & - & - & 0.1664 \\
\hline & Levene's test for equality of variances & 2.1730 & 7 & 24 & 0.0740 \\
\hline
\end{tabular}

and casting processes. It is expected that futures studies will confirm the technical and economic viability for commercial exploitation of GFRP waste recyclates incorporation into PC composites.

\section{Acknowledgements}

The financial support of 'ADI, Agência de Inovação', under 'QREN, Quadro de Referência de Estratégia Nacional (ON.2)' Program, as well as the technical support of 'Alto-Perfis Pultrudidos Lda.', are gratefully acknowledged. We also wish to thank Anthony Danko for reviewing this manuscript.

\section{Appendix A}

See Table A1 and Fig. A1.

\section{References}

[1] Chin JW. Material aspects of fibre-reinforced polymer composites in infrastructures. NISTIR 5888, Building and Fire Research Laboratory, Gaithesburg; 1996.

[2] Karbhari VM. Use of composite materials in civil infrastructures in Japan. Maryland: International Technology Research Institute; 1998.

[3] Broekel J, Scharr G. The specialities of fibre reinforced plastics in terms of product lifecycle management. J Mater Process Technol 2005;162-163:725-9.

[4] Starr TF, Ketel J. Composites and pultrusion. In: Starr T, editor. Pultrusion for engineers. Cambridge: Woodhead Publishing Limited; 2000. p. 1-18.

[5] Pimenta S, Pinho ST. Recycling carbon fibre reinforced polymers for structura applications: technology review and market outlook. Waste Manage 2011;31(2):378-92.

[6] Pickering SJ. Recycling technologies for thermoset composite materials current status. Composites Part A 2006;37(8):1206-15.

[7] Conroy A, Halliwell S, Reynolds T. Composite recycling in the construction industry. Composites Part A 2006;37(8):1216-22.

[8] Sims G, Bishop G. UK Polymer composites sector - foresight study and competitive analysis. NPL MATC(A)80, National Physical Laboratory Materials Center, UK; 2001.

[9] Bartholomew K. Fiberglass reinforced plastics recycling. Minnesota Technical Assistance Program Report; 2004 <www.mntap.umn.edu/fiber/report1204.pdf>.

[10] Palmer J, Ghita OR, Savage L, Evans KE. Successful closed-loop recycling of thermoset composites. Composites Part A 2009;40(4):490-8.

[11] Demura K, Ohama Y, Stoh T. Properties of artificial wood using FRP powder. In: Disposal and recycling of organic and polymeric construction materials, proceedings of the international RILEM workshop, Tokyo, 26-28 Mars; 1995.

[12] George S, Dillman S. Recycled fiberglass composite as a reinforcing filler in post-consumer recycled HDPE plastic lumber. In: Proceedings of annual technical conference of society of plastics engineers (SPE/ANTEC 2000), Orlando; 7-11 May, 2000.

[13] Itoh T, Kaneko M. Pavement blocks from recycled GFRP material. In: Proceedings of convention and trade show composites fabricators association (COMPOSITES 2002), Atlanta, 25-27 September; 2002.

[14] Woodside AR, Woodward WDH, Jellie JH. Highway engineering material tests at Ulster University. Project report; June 2003.

[15] Reynolds TN, Halliwell S, Conroy A. Markets for FRP recyclate. Inst Wastes Manage, Sci Tech Rev 2004;5:29-34

[16] Adolphs G, Branca, A. New Approaches in Recycling Thermoset Composites. In: Proceedings of convention and trade show composites fabricators association (COMPOSITES 2001), Tampa; 3-6 October, 2001.

[17] Halliwell S. End of life options for composite waste: recycle, reuse or dispose? Best practice guide. National composite network; $2006<$ http:// www.tech.plym.ac.uk/sme/mats324/Publications/ Halliwell\%20on\%20composites\%20EOL.pdf>.

[18] Asokan P, Osmani M, Price ADF. Assessing the recycling potential of glass fibre reinforced plastic waste in concrete and cement composites. J Clean Prod 2009;17(9):821-9.

[19] Asokan P, Osmani M, Price ADF. Improvement of the mechanical properties of glass fibre reinforced plastic waste powder filled concrete. Constr Build Mater 2010;24(4):448-60.
[20] Tittarelli F, Moriconi G. Use of GRP industrial by-products in cement based composites. Cem Concr Compos 2010;32(3):219-25.

[21] Tittarelli F, Kawashima S, Tregger N, Moriconi G, Shah SP. Effect of GRP byproduct addition on plastic and hardened properties of cement mortars. In: Proceedings of 2nd international conference on sustainable construction materials and technologies, Ancona; 28-30 June, 2010.

[22] Correia JR, Almeida NM, Figueira JR. Recycling of FRP composites: reusing fine GFRP in concrete mixtures. J Clean Prod 2011;19(15):1745-53.

[23] Osmani M, Pappu A. An assessment of the compressive strength of glass reinforced plastic waste filled concrete for potential applications in construction. Concr Res Lett 2010;1(1):1-5.

[24] Ogi K, Shinoda T, Mizui M. Strength in concrete reinforced with recycled CFRP pieces. Composites Part A 2005;36(7):893-902.

[25] Fowler DW. Polymers in concrete: a vision for the 21st century. Cem Concr Compos 1999;21(5-6):449-52.

[26] Czarnecki L. Polymer in concrete on the edge of the millennium. In: Proceedings of the 10th international conference on polymers in concrete (ICPIC 2001), Honolulu; May 2001.

[27] Bhutta MAR, Ohama Y. Recent status of research and development of concretepolymer composites in Japan. Concr Res Lett 2010;1(4):125-30.

[28] ACI 548.1R-09. Guide for the use of polymers in concrete. Report of ACI Committee 548, American Concrete Institute, Detroit; 2009.

[29] Ribeiro MCS, Tavares CML, Ferreira AJM. Chemical resistance of epoxy and polyester polymer concrete to acids and salts. J Polym Eng 2002;22:27-44.

[30] Tavares CML, Ribeiro MCS, Ferreira AJM, Guedes RM. Creep behavior of FRPreinforced polymer concrete. Compos Struct 2002;57(1-4):47-51.

[31] Ribeiro MCS, Nóvoa PR, Ferreira AJM, Marques ATM. Flexural performance of polyester and epoxy polymer mortars under severe thermal conditions. Cem Concr Compos 2004;26(7):803-9.

[32] Ribeiro MCS, Ferreira AJM, Marques AT. Natural and artificial weathering effects on long-term performance of polymer mortars. Mech Compos Mater 2009;45(5):515-26.

[33] Nóvoa PRO, Ribeiro MCS, Ferreira AJM, Marques ATM. Mechanical characterization of lightweight polymer mortar modified with cork granules. Compos Sci Technol 2004;64(13-14):2197-205.

[34] Bignozzi MC, Saccani A, Sandrolini F. New polymer mortars containing polymeric wastes. Part 1: microstructure and mechanical properties. Composites Part A 2000;31(2):97-106.

[35] Bignozzi MC, Saccani A, Sandrolini F. New polymer mortars containing polymeric wastes. Part 2: dynamic mechanical and dieletric behavior. Composites Part A 2002;33(2):205-11.

[36] Rebeiz KS, Serhal SP, Craft AP. Properties of polymer concrete using fly ash. J Mater Civ Eng 2004;16(1):15-9.

[37] Ribeiro MCS, Nóvoa PRO, Marques ATM, Ferreira AJM. Mechanical characterization of lightweight wood-modified polymer concrete. Ciê Tecnol Mater 2004;16:81-7.

[38] Reis JML, Jurumenha MAG. Experimental investigation on the effects of recycled aggregate on fracture behaviour of polymer concrete. Mater Res 2011;14(3):326-30.

[39] DeRosa R, Telefeyan E, Gaustad G, Mayes S. Strength and microscopic investigation of unsaturated polyester BMC reinforced with SMC recyclate. J Thermoplast Compos 2005;18(4):333-49.

[40] Wong KH, Mohammed DS, Pickering SJ, Brooks R. Effect of coupling agents on reinforcing potential of recycled carbon fibre for polypropylene composite. Compos Sci Technol 2012;72:835-44.

[41] Ribeiro MCS, Meixedo JP, Fiúza A, Dinis ML, Castro ACM, Silva FJG, et al. Mechanical behaviour analysis of polyester polymer mortars modified with recycled GFRP waste materials. World Acad Sci, Eng Technol 2011;75:365-71.

[42] Correia SL, Souza FL, Dienstmann G, Segadães AM. Assessment of the recycling potential of fresh concrete using a factorial design of experiments. Waste Manage 2009;29(11):2886-91.

[43] Gorninsky JP, Dal Molin DC, Kazmierczak CS. Study of the modulus of elasticity of polymer concrete compounds and comparative assessment of polymer concrete and Portland cement concrete. Cem Concr Res 2004;34(11):2091-5.

[44] Muthukumar M, Mohan D. Optimization of mechanical properties of polymer concrete and mix design recommendation based on design of experiments. J Appl Polym Sci 2004;94:1107-16.

[45] Ozbay E, Oztas A, Baykasoglu A, Ozbebek H. Investigating mix proportions of high strength self compacting concrete by using Taguchi method. Constr Build Mater 2009;23(2):694-702.

[46] Ribeiro MCS, Nóvoa PRO, Marques ATM, Ferreira AJM. Bending characteristics of resin concretes. Mater Res 2003;6(2):247-54.

[47] Chmielewska B, Czarnecki L, Sustersic J, Zajc A. The influence of silane coupling agents on the polymer mortar. Cem Concr Compos 2006;28:803-10. 
[48] RILEM CPT PC-2. Method of making polymer concrete and mortar specimens. Technical Committee 113, RILEM, UK; 1995.

[49] RILEM CPT PCM-8. Method of test for flexural strength and deflection of polymer-modified mortars. Technical Committee 113, RILEM, UK; 1995.

[50] UNE 83821:1992. Morteros: Métodos de ensayo; Morteros endurecidos; Determinación de las resistências a flexión y a compressión. UNE, Spain; 1992.

[51] EN 196-1:2005. Methods of testing cement - part 1: determination of strength. European Committee for Standardization; 2005.
[52] Montgomery DC. Design and Analysis of Experiments. NY: John Wiley \& Sons, Inc.; 2001.

[53] Shapiro SS, Wilk MB. Analysis of variance test for normality (complete samples). Biometrika 1965;52(3-4):591-611.

[54] Lix LM, Keselman JC, Keselman HJ. Consequences of assumption violations revisited: a quantitative review of alternatives to the one-way analysis of variance F-test. Rev Educ Res 1996;66(4):579-619. 